\title{
Is prophylactic removal of impacted mandibular third molar justified in all patients? A prospective clinical study of patients $\mathbf{5 0}$ years and above
}

\author{
Charles E Anyanechi ${ }^{1}$, Birch D Saheeb ${ }^{2}$, Uchenna C Okechi ${ }^{3}$
}

1. Department of Oral and Maxillofacial Surgery, University of Calabar/University of Calabar Teaching Hospital Calabar, Nigeria. E-mail: ceanyanechi@gmail.com

2. Department of Oral and Maxillofacial Surgery, University of Benin/University of Benin Teaching Hospital Benin-City, Nigeria. E-mail: dauda2000@gmail.com

3. Department of Oral and Maxillofacial Surgery, Faculty of Dentistry, University of Nigeria, Ituku/Ozalla, Enugu, Nigeria. E-mail: uchenna.okechi@unn.edu.ng

Work attributed to: Department of Oral and Maxillofacial Surgery, University of Calabar Teaching Hospital Calabar, Nigeria.

\begin{abstract}
Background: The prophylactic extraction of asymptomatic impacted mandibular third molar is a contentious issue in dental practice.

Objective: To evaluate symptomatic impacted mandibular third molars in patients 50 years and above, and determine the burden of the impaction on the adjacent second molar.

Methods: This was a prospective clinical study over a three-year period. The diagnosis of impacted mandibular third molar and their associated pathology was made by clinical and radiological examination. The data obtained were age, sex, type of impaction, reason for surgical extraction, and the clinical condition of the adjacent second molar.

Results: Patients 50 years and above were $33.4 \%$, and those with impaction $22.8 \%$, while the symptomatic cases were in $18.4 \%$ patients. The age of the patients ranged from 52 to 84 years with male: female ratio, 2.3:1. In all the asymptomatic impactions, the adjacent second molars were disease-free, whereas $73.6 \%$ of the adjacent second molar related to symptomatic cases were asymptomatic $(\mathrm{P}=0.001)$.

Conclusion: This study showed that $15.9 \%$ of impactions in $18.4 \%$ of patients were symptomatic and required surgical extraction, whereas the burden of impaction on the adjacent second molar was $26.4 \%$, and these required only preventive and restorative treatments.
\end{abstract}

Keywords: Mandible, impaction, second molar, third molar, prognosis.

DOI: https://dx.doi.org/10.4314/ahs.v19i1.55

Cite as: Anyanechi CE, Saheeb BD, UC O. Is prophylactic removal of impacted mandibular third molar justified in all patients? A prospective clinical study of patients 50 years and above. Afri Health Sci. 2019;19(1). 1789-1794. bttps:// dx.doi. org/10.4314/ abs. v19i1.55

\section{Corresponding author:}

Charles E Anyanechi,

Department of Oral and Maxillofacial Surgery,

University of Calabar Teaching Hospital

P. O. Box 3446, Eastern Highway

540001, Calabar, Nigeria.

Phone number: +2348059383922

Email: ceanyanechi@gmail.com

\section{Introduction}

Across the globe, impaction of mandibular third molars is common among the general population with frequency ranging from $22.0 \%$ to $66.0 \%{ }^{1-3}$ When diagnosed in adolescent or young adult, the prognosis of such impacted mandibular wisdom teeth cannot be determined immediately because over time, it is influenced by many confounding variables which may be local, systemic or both. ${ }^{4-6}$ When afflicted by disease, researchers and clini-

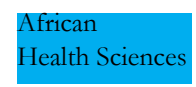

(C) 2019 Anyanechi et al. Licensee African Health Sciences. This is an Open Access article distributed under the terms of the Creative commons Attribution License (https://creativecommons.org/licenses/BY/4.0), which permits unrestricted use, distribution, and reproduction in any medium, provided the original work is properly cited. 
cians generally agree that it should be extracted to relieve patients' pain and discomfort. ${ }^{7,8}$ On the contrary, others have suggested that this dentition plays no significant role in the oral cavity except to cause disease and recommended extraction even in the absence of an obvious pathological condition. ${ }^{9-11}$ This practice is controversial among researchers and clinicians in dental surgery and oral and maxillofacial surgery across the globe, as there is no consensus agreement in this regard. ${ }^{9-12}$ The question has always been whether early surgical intervention in adolescents and young adults is justified or not in asymptomatic cases? The debate centres on whether the health needs of the patient justify the cost of the extraction in terms of the discomfort experienced post-operatively, surgical cost, and the economic burden on government and other non-governmental organizations in some countries that may partly bear the surgical bills. However, the extraction of impacted mandibular third molar in the absence of any pathology is common in Europe and America. ${ }^{10,12}$ In the study environment, this practice is not common and the patients affected live their normal life with it, except when it is involved in disease that make them present in hospitals or dental clinics for treatment. ${ }^{13,14}$ However, adequate statistics is required to identify and address the peculiar needs of the patients afflicted by this condition, particularly those with limited access to oral health as reported earlier in our environment. ${ }^{15}$ This study evaluates symptomatic impacted mandibular third molars in patients 50 years and above, and determines the burden of the impaction on the adjacent second molar.

\section{Patients and methods}

This is a prospective clinical study which evaluated symptomatic impacted mandibular third molars in patients 50 years and above, and determined the burden of the impaction on the adjacent second molar over a three-year period. The study was carried out at the Dental and Maxillo-facial Surgery clinic of the tertiary health institution between January 2014 and December 2016. Ethical approval was obtained from the Research and Ethics Committee of the institution before the commencement of the study, which followed the 1975 (as revised in 2008) Declaration of Helsinki on Medical Protocol and Ethics. Also, written informed consent was obtained from all the subjects before being enrolled in the study. The diagnosis of impacted mandibular third molar and their associated pathology with the condition of the adjacent second molar was made by clinical and radiological (mandibular lateral oblique radiograph) evaluation.

Inclusion criteria were patients 50 years and above, both gender with impacted mandibular third molars. Those patients who were below 50 years or had lost the adjacent mandibular second molar were excluded from the study.

The data obtained were recorded in a pro-forma and included age, sex, type of impaction, reason for surgical extraction, and the clinical condition of the adjacent second molar tooth. The data were analyzed with EPI Info 2008 version software (CDC, Atlanta, GA, USA). Analysis included simple frequency charts, descriptive statistics and test of significance. $P$ values $<0.05$ are considered significant.

\section{Results}

Overall, 3,778 patients were seen during the study period; those 50 years and above were 1,261(33.4\%). Patients who had impacted mandibular third molars were $287 / 1261(22.8 \%)$ with 333 impactions, while those that were symptomatic were seen in 53/287(18.4\%) patients. The symptomatic third molars that required surgical extraction were unilateral in all cases $(n=53 / 333,15.9 \%)$. The reasons for surgical intervention were dental caries and its sequelae $(n=39,73.6 \%)$, chronic gingivitis $(n=8$, $15.1 \%)$ and pericoronitis $(n=6,11.3 \%)$. The age of the patients ranged from 52 to 84 years with mean as $65 \pm 3.8$ years. The distribution of impacted third molar in relation to age and sex is shown in table 1. 


\section{Table 1: Distribution of symptomatic impacted mandibular third molars in relation to age and sex.}

Type of impaction
Age in years $(\%)$
$\operatorname{Sex}(\%)$
Total (\%)

\begin{tabular}{lccccccc} 
& $50-59$ & $60-69$ & $70-79$ & $80-89$ & Male & Female & \\
\hline Mesio-angular & $12(22.6)$ & $8(15.1)$ & $7(13.2)$ & $2(3.8)$ & $19(35.8)$ & $10(18.9)$ & $29(54.7)$ \\
Vertical & $5(9.4)$ & $7(13.2)$ & $5(9.4)$ & $1(1.9)$ & $13(24.5)$ & $5(9.4)$ & $18(33.9)$ \\
Disto-angular & $3(5.7)$ & $0(0.0)$ & $0(0.0)$ & $0(0.0)$ & $2(3.8)$ & $1(1.9)$ & $3(5.7)$ \\
Horizontal & $2(3.8)$ & $1(1.9)$ & $0(0.0)$ & $0(0.0)$ & $3(5.7)$ & $0(0.0)$ & $3(5.7)$ \\
Total & $22(41.5)$ & $16(30.2)$ & $12(22.6)$ & $3(5.7)$ & $37(67.8)$ & $16(30.2)$ & $53(100.0)$ \\
\hline
\end{tabular}

There were more males than females with male: female ratio of 2.3:1. Males out-numbered females in all the age categories $(\mathrm{P}=0.001)$. As the age increased, patients with symptomatic impacted third molars decreased, and this was significant $(\mathrm{P}=0.01)$. Mesio-angular impaction was the most common type of impaction in this series $(n=29$, $54.7 \%)$.

In all the asymptomatic impacted third molars, the adjacent second molars were disease-free. The adjacent second molar tooth related to symptomatic cases showed $39 / 53(73.6 \%)$ to be asymptomatic $(\mathrm{P}=0.001)$, while the symptomatic second molars were $14 / 53$ (26.4\%). The symptomatic cases were due to chronic reversible pulpitis secondary to dental caries $(\mathrm{n}=9,17.0 \%)$ and chronic gingivitis ( $\mathrm{n}=5,9.4 \%$ ) which were treated by amalgam fillings, and scaling and polishing respectively.

\section{Discussion}

This study showed that $15.9 \%$ of impacted mandibular third molars in $18.4 \%$ of patients were symptomatic, and were surgically removed while the rest $84.1 \%$ in $81.6 \%$ patients were asymptomatic. In addition, the burden of impaction on the adjacent second molars was $26.4 \%$, and these required preventive and restorative treatments, whereas $73.6 \%$ were disease-free. Consequently, it can be stated unequivocally that early surgical intervention in all cases of impaction is not justified, unless they are symptomatic. This finding supports some earlier views, ${ }^{10,12,16}$ but is contrary to those who advocate for extraction of the tooth whether symptomatic or asymptomatic in all adolescents and young adults. ${ }^{17,18}$ The reasons for prophylactic surgical extraction are the need to minimize the risk of disease development, reduction of probability of mandibular angle fracture, difficulty of surgery with increasing age and the third molar not having any definitive role to play in the mouth. The surgical morbidities such as pain, swelling and trismus are almost always constant in occurrence after the surgical extraction, in addition to the post-operative complications which occur in most cases. ${ }^{7,8}$ Furthermore, the psychological trauma experienced by some patients during the surgery, medical bills borne by the patients or partly by governmental or non-governmental organization in some situations, loss of working hours and social life during the post-operative recovery period after the treatment also impact negatively on the patient and the larger society. ${ }^{9-12}$ It should also be noted that Bodner et al. ${ }^{19}$ stated that partially erupted mandibular third molars contribute to the prevention of condylar fractures if left in-situ without extraction, whereas Retzik et al. ${ }^{20}$ on the contrary, showed that mandibles containing unerupted or impacted mandibular third molars fractured at approximately $60 \%$ of the force required to fracture the mandible containing fully erupted mandibular third molars.

In consideration of the patients in this study whose impacted third molars were symptomatic and required surgical extraction, the outcome seems to suggest that leav- 
ing impacted third molars in-situ unless they create or become associated with a pathological condition is the better management option, and the decision to extract asymptomatic cases will be better acceptable when the decision is made on individual basis which reflects their health needs and access to standard oral health care facility as stated by Boughner, ${ }^{21}$ while corroborating other earlier reports across the globe. ${ }^{22-27}$ On the contrary, the American Association of Oral and Maxillofacial Surgeons (AAOMS) considers all third molar whether impacted or not, to pose a significant risk to the patients' well-being and recommended extraction in all cases including those that are asymptomatic. ${ }^{28-30}$ However, researchers in Cana$\mathrm{da}$ noted that there is currently insufficient evidence supporting or refuting the practice of prophylactic removal of asymptomatic third molars, but still advocates that each case should be treated on its merit. ${ }^{31}$

The problem with impacted mandibular third molars is that they are associated with various disease conditions that affect the mandible, gingiva and adjacent dentition. ${ }^{5,32,33}$ The pathological conditions that afflicted the impacted third molars and the adjacent second molar may be a direct consequence of the abnormal anatomical relationship between them because of the impaction. ${ }^{5,13}$ This abnormal anatomical relationship creates stagnation area for accumulation of food debris, proliferation of micro-organisms, formation of dental plaque, and because of the patients' inability to properly access that part of the mouth during routine oral hygiene procedure over time, results in disease. However, it is not clear if the age-associated risk of disease ${ }^{32}$ (i.e., the more elderly the patient, the greater the apparent risk posed by impacted mandibular third molars) is due to the increased possibility of bacterial accumulation and tissue inflammation with time, which is part of the reason why this study was embarked upon this age category. It is also not clear if the position of the impacted third molar at the back of the mouth, which makes it more difficult to clean, contributes to the reported association of asymptomatic impacted third molars with caries and periodontal disease. ${ }^{32,33}$ That mesio-angular impaction was the most common type of impaction in this series is in keeping with the findings of most other studies. ${ }^{2,3,34}$

The question that oral health care professionals and policy formulators will answer is whether the risks of retain- ing impacted mandibular third molars outweigh the risks of extraction? This paper has provided a guide in this direction. However, the AAOMS White Paper cautions that retained third molars, impacted or otherwise, require routine clinical observation. ${ }^{29}$ Of course, good oral health requires that all teeth be regularly checked once or twice yearly. Consequently, the burden of monitoring retained impacted third molars is relatively minor and cheaper, with the exception of subjects who are unable or unwilling to access regular dental care. ${ }^{21}$ In these circumstances, specific treatment plans must be developed when possible. ${ }^{11,21-26}$

This study showed that males were affected more than females, but the frequency of occurrence decreased as the years increased. The gender mostly affected is not conclusive in the literature as earlier studies have shown variation in this regard prompting the authors to suggest that it may be due to genetic inheritance in relation to the population studied. ${ }^{3,5,6,18,21}$ It is generally agreed that the extraction of symptomatic impacted mandibular third molars is an effective and definitive treatment option to help maintain good patient oral health. The existing literature also suggests that the age at which to determine whether or not to extract impacted mandibular third molars is still under debate. Osborn et al. ${ }^{35}$ showed that complications are less likely to occur in patients aged 35 to 83 years than in subjects aged 12 to 24 years. They stated that complications occur mostly in patients 25 to 34 years. On the contrary, Kim et al. ${ }^{7}$ noted that the extractions should be done before 24 years of age particularly in females, and that older patients are at greater risk of post-operative complications and permanent sequelae.

\section{Conclusion}

This study showed that $15.9 \%$ of impacted mandibular third molars in $18.4 \%$ of patients were symptomatic, requiring surgical extraction, whereas the burden of impaction on the adjacent second molar was $26.4 \%$ without the need for their removal, suggesting that leaving impacted third molars in-situ unless they create or become associated with a pathological condition is the better management option. The extraction of symptomatic impacted mandibular third molars is an effective and definitive treatment to help maintain good patient oral health, but should not be extended to asymptomatic cases. In such cases, the burden of monitoring retained impacted mandibular third molars is relatively minor and cheaper, with 
the exception of subjects who are unable or unwilling to access regular dental care, in which case, specific treatment plans must be developed when possible.

\section{Conflict of interest}

None declared.

\section{References}

1. de Santana-Santos T, de Souza-Santos AA, Martins-Filho PR, et al. Prediction of post-operative facial swelling, pain and trismus following third molar surgery based on preoperative variables. Med Oral Patol Oral Cir Bucal. 2013; 18:e65-70.

2. Eshghpour M, Nejat AH. Dry socket following surgical removal of impacted third molar in an Iranian population: Incidence and risk factors. Nig J Clin Pract. 2013; 16: 496-500.

3. Msagati F, Simon EN, Owibingire S. Pattern of occurrence and treatment of impacted teeth at the Muhimbili National Hospital, Dar es Salam, Tanzania. BMC Oral Health. 2013; 13: 37-42.

4. Chuang SK, Perrott DH, Susarla SM, et al. Risk factors for inflammatory complications following third molar surgery in adults. J Oral Maxillofac Surg. 2008; 66: 22132218.

5. Marciani RD. Complications of third molar surgery and their management. Atlas Oral Maxillofac Surg Clin North Am. 2012; 20: 233-251.

6. Jun SH, Kim CH, Ahn JS, et al. Anatomical differences in lower third molars visualized by $2 \mathrm{D}$ and 3D X-ray imaging: clinical outcomes after extraction. Int J Oral Maxillofac Surg. 2013; 42: 489-96.

7. Kim JW, Cha IH, Kim SJ, et al. Which risk factors are associated with neurosensory deficits of inferior alveolar nerve after mandibular third molar extraction? J Oral Maxillofac Surg. 2012; 70: 2508-2514.

8. Anyanechi CE, Saheeb BD. Nerve morbidity after mandibular third molar surgery: A prospective study of two cohorts of patients. J Neurol Neurosci. 2015; 6: 43 (15). PubMed.

9. Friedman JW. Containing the costs of third molar surgery: a dilemma for health insurance. Public Health Rep. 1983; 98: 379-384 PubMed.

10. Song F, Landes DP, Glenny AM, et al. Prophylactic removal of impacted third molars: an assessment of published reviews. Br Dent J. 1997; 182: 339-346 PubMed. 11. Costa MG, Pazzini CA, Pantuzo MC, et al. Is there justification for the prophylactic extraction of third molars? A systematic review. Braz Oral Res. 2013; 27: 183-188 PubMed.

12. Friedman JW. The prophylactic extraction of third molars: a public health hazard. Am J Public Health. 2007; 97: 1554-1559 PubMed.

13. Chukwuneke FN. A comparative study of the effect of different third molar impactions on postoperative morbidity following lower third molar surgery. Int J Med Health Dev. 2006; 11: 82-87.

14. Anyanechi CE, Saheeb BD. The efficacy of tincture of benzoin compound in the management of extraction sockets of mesio-angularly impacted mandibular third molar. Oral Surg. 2013; 6:137-141 PubMed.

15. Anyanechi CE, Saheeb BD. Reasons underlying failure to seek early dental treatment among patients presenting in a Nigerian tertiary hospital. J Med Biomed Res. 2013; 12: 37-45 PubMed.

16. Edwards MJ, Brickley MR, Goodey RD, et al. The cost, effectiveness and cost effectiveness of removal and retention of asymptomatic, disease free third molars. $\mathrm{Br}$ Dent J. 1999; 187: 380-384 PubMed.

17. Hanson BP, Cummings P, Rivara FP, et al. The association of third molars with mandibular angle fractures: a meta-analysis. J Can Dent Assoc. 2004; 70: 39-43 PubMed. 18. Almendros-Marques N, Alaejos-Algarra E, Quinteros-Borgarello M, et al. Factors influencing the prophylactic removal of asymptomatic impacted lower third molars. Int J Oral Maxillofac Surg. 2008; 37: 29-35 PubMed. 19. Bodner L, Brennan PA, Mcleod NM. Characteristics of iatrogenic mandibular fractures associated with tooth removal: review and analysis of 189 cases. Br J Oral Maxillofac Surg. 2011; 49: 567-572.

20. Reitzik M, Lownie JF, Cleaton-Jones JP, et al. Experimental fractures of monkeys' mandibles. Int J Oral Surg. 1978; 7: 100-103 PubMed.

21. Boughner JF. Maintaining perspective on third molar extraction. J Can Dent Assoc. 2013; 79: d 106.

22. American Public Health Association. Opposition to Prophylactic Removal of Third Molars (Wisdom Teeth). Policy Statement Database. Policy Number: 20085. [accessed 2017 Aug 26] Available: http://www.apha.org/advocacy/policy/policysearch/default.htm?id=1371

23. Ahlqwist M, GrÖndahl HD. Prevalence of impacted teeth and associated pathology in middle aged and older Swedish women. Community Dent Oral Epidemiol. 1991; 19: 116-119 PubMed. 
24. Scottish Intercollegiate Guidelines Network. Management of Unerupted and Impacted Third Molar Teeth: A National Clinical Guideline. Edinburgh: Scottish Intercollegiate Guidelines Network, Royal College of Physicians; 1999. p. 36.

25. Kandasamy S, Rinchuse DJ, Rinchuse DJ. The wisdom behind third molar extractions. Aust Dent J. 2009; 54 : 284-292 PubMed.

26. Suska F, Kjeller G, Molander A, et al. Health Technology Assessment: Removal of impacted wisdom teeth. Göteborg: Regional HTA Centre, Västra Götaland; 2010. p. 51.

27. Stordeur S, Eyssen M. Prophylactic removal of pathology-free wisdom teeth: rapid assessment. Good Clinical Practice (GCP). Brussels: Belgian Health Care Knowledge Centre (KCE). 2012. KCE Report. 182C. D/2012/10.273/49.

28. Blakey GH, Marciani RD,Haug RH, et al. Periodontal pathology associated with asymptomatic third molars. J Oral Maxillofac Surg 2002; 60: 1227-33 PubMed.

29. Haug RH, Abdul-Majid J, Blakey GH, et al. Evidence-based decision making: The third molar. Dent Clin North Am. 2009; 53: 77-96. PubMed.
30. Blakey GH, Gelesko S, Marciani RD, et al. Third molars and periodontal pathology in American adolescents and young adults: a prevalence study. J Oral Maxillofac Surg. 2010; 68: 325-329.

31. Canadian Agency for Drugs and Technologies in Health. Health Technology Inquiry Service. Health Technology Assessment Prophylactic Removal of Wisdom Teeth: A Review of the Clinical Benefit and Guidelines; 2010. p 1-15.

32. Fisher EL, Moss KL, Offenbacher S, et al. Third molar caries experience in middle-aged and older Americans: a prevalence study. J Oral Maxillofac Surg. 2010; 68: 634640.

33. Moss KL, Beck JD, Mauriello SM, et al. Third molar periodontal pathology and caries in senior adults. J Oral Maxillofac Surg. 2007; 65: 103-108.

34. Anyanechi CE, Saheeb BD. The complications associated with the extraction of asymptomatic impacted mandibular third molars: A prospective clinical study of 63 patients. J Neurol Neurosci. 2016; 7: 98(1-5). PubMed.

35. Osborn TP, Frederickson G, Small IA, et al. A prospective study of complications related to mandibular third molar surgery. J Oral Maxillofac Surg. 1985; 43: $767-$ 769. 